\title{
Custom Ocular Prosthesis for Enucleated Eye: A Case Report
}

\author{
Surya Narayan Pun, Rojina Shakya, Galav Adhikari, Prakash Kumar Parajuli, Raj Kumar Singh, \\ Pramita Suwal.
}

Department Of Prosthodontics, BPKIHS, Dharan

\section{Correspondence}

Dr. Surya Narayan Pun, Junior

Resident, Department Of

Prosthodontics, BPKIHS, Dharan

Email: drsuryapun@gmail.com

DOI: http://dx.doi.org/10.3126/ jcmsn.v12i3.16018

Article received: July $27^{\text {th }} 2016$

Article accepted: Aug 252016

\section{ABSTRACT}

The unfortunate loss or absence of an eye may be caused by a congenital defect, irreparable trauma, tumor, sympathetic ophthalmia, or the need for histologic confirmation of a suspected diagnosis. Early rehabilitation with suitable prosthesis is recommended to ease the mind of the afflicted. An ocular prosthesis is a maxillofacial prosthesis that artificially replaces an eye missing as a result of trauma, surgery, or congenital absence. A custom ocular prosthesis has advantage of close adaptation to the tissue bed, provides maximum comfort and restores full physiological function to the accessory organs of the eye.

Key words: Enucleation; eye; ocular; prosthesis

Citation: Pun SN, Shakya R, Adhikari A, Parajuli PK, Singh RK, Suwal P. Custom Ocular Prosthesis for Enucleated Eye: A Case Report. JCMS Nepal. 2016;12(2):127-30.

\section{INTRODUCTION}

Eye is an important component of facial expression and the vital organ of vision. The unfortunate loss or absence of an eye may be caused by a congenital defect, irreparable trauma, tumor, sympathetic ophthalmia, or the need for histologic confirmation of a suspected diagnosis. ${ }^{1}$ Apart from the obvious impairment of visual function, the loss of an eye also results in noticeable physical deformity which compounds the psychological burden of the patients. Early rehabilitation with suitable prosthesis is recommended to ease the mind of the afflicted.

Depending on the severity of the situation, the surgical management may include one of the three approaches: evisceration, enucleation, or exenteration. Evisceration is the surgical procedure wherein the intraocular contents of the globe are removed, leaving the sclera, Tenon's capsule, conjunctiva, extraocular muscles, and optic nerve undisturbed; the cornea may be retained or excised. Enucleation is the surgical removal of the globe and a portion of the optic nerve from the orbit. The choice between evisceration and enucleation may be difficult, because the indications are not always clearly defined. Enucleation is often considered the treatment of choice for primary intraocular malignancies because it permits histopathologic examination of the intact globe, as well as determination of intraneural or extrascleral spread of the disease. Orbital exenteration is the en bloc removal of the entire orbit, usually involving partial or total removal of the eyelids, and is performed primarily for eradication of malignant orbital tumor. ${ }^{2}$

An ocular prosthesis is a maxillofacial prosthesis that artificially replaces an eye missing as a result of trauma, surgery, or congenital absence. The prosthesis does not replace missing eyelids or adjacent skin, mucosa or muscle. ${ }^{3}$

Frenchman Ambroise Pare, a pioneer of maxillofacial prosthodontics, was the first to use both glass and porcelain eyes. During and after the World War II, artificial glass eyes were replaced by acrylic. Unlike glass eyes, an acrylic resin eye was easy to fit and adjust, unbreakable, inert to ocular fluid, esthetically sound, long lasting and easier to fabricate. ${ }^{4-6}$

Ocular prosthesis can be classified as stock shell and custom-made prosthesis. The close contact of Custom-made ocular prosthesis with the tissue bed improves tissue health by reducing fluid accumulation in tissue-prosthesis interface thereby decreasing the chances of tissue irritation and bacterial growth. Custom ocular prostheses are also known to distribute the pressure more equally and decrease the incidence of conjunctival abrasion as compared to stock ocular prostheses. ${ }^{7,8}$

\section{CASE REPORT}

A 46-year-old male patient reported to the 
Custom Ocular Prosthesis for Enucleated Eye

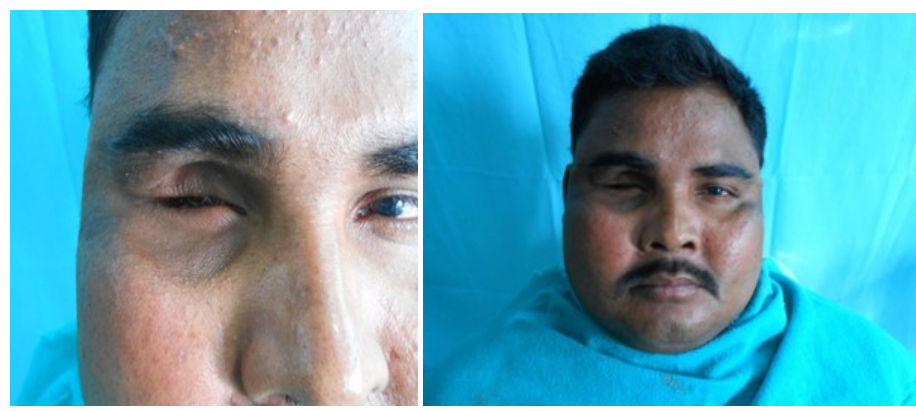

Fig1: Pre-treatment photograph
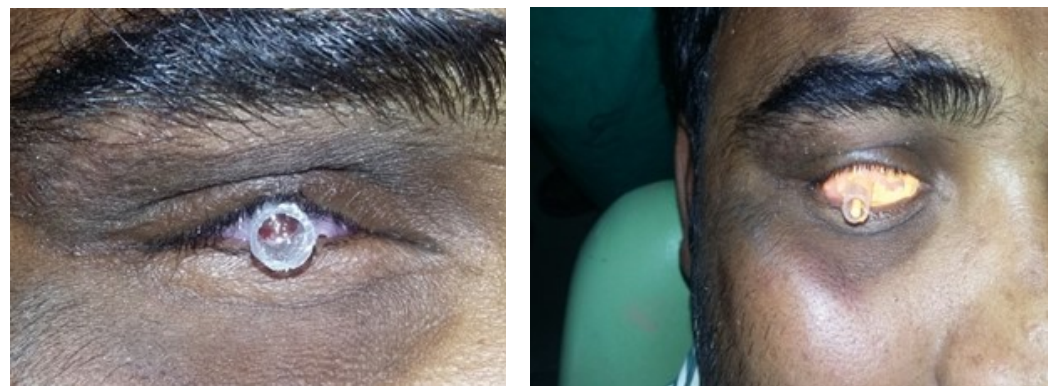

Fig 2: Custom tray with screwing syringe tip

Fig 3: Placement of cusom tray and impression making
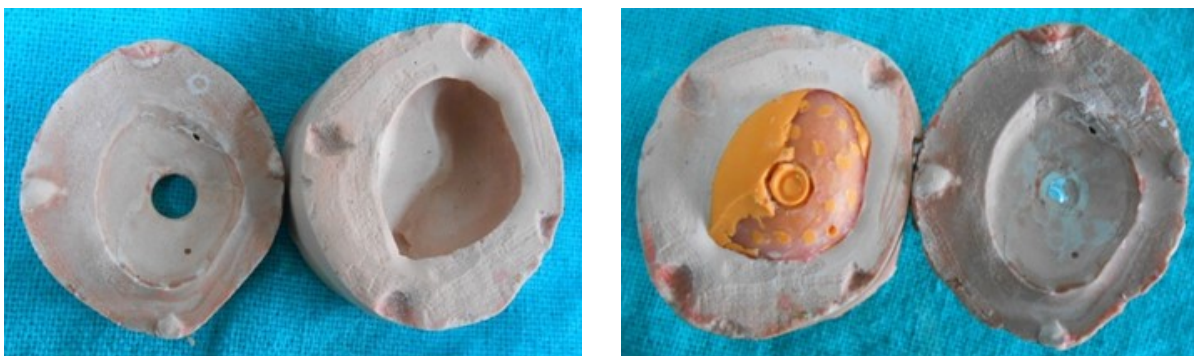

Fig 4: Impression pouring

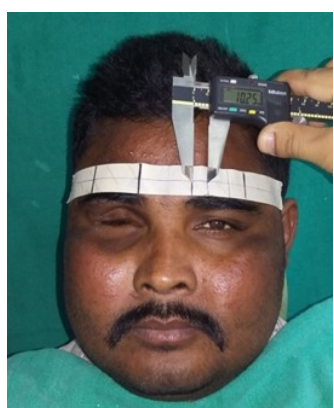

Fig 5: Measurement for position of iris

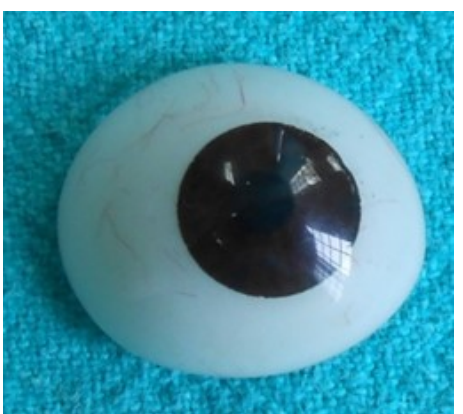

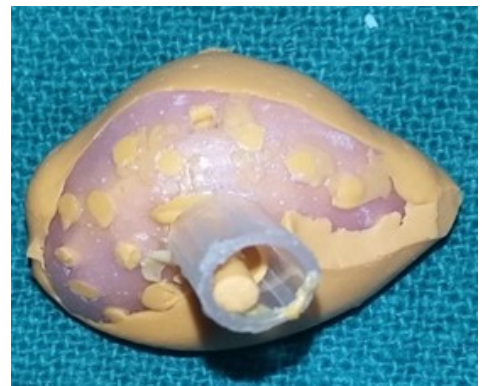

JCMS Nepal 2016;12(2):78-80

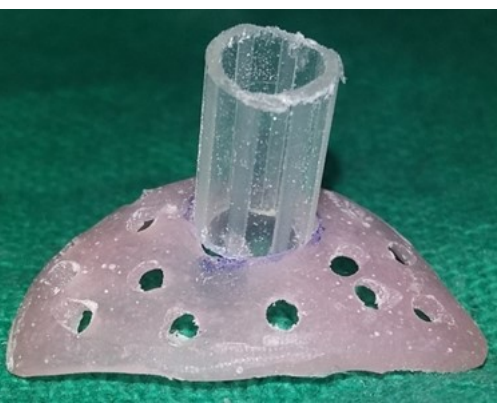

Fig 6: Prefab stock eye

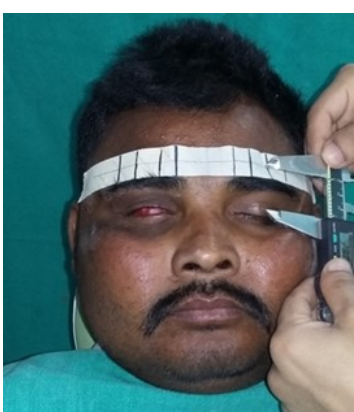

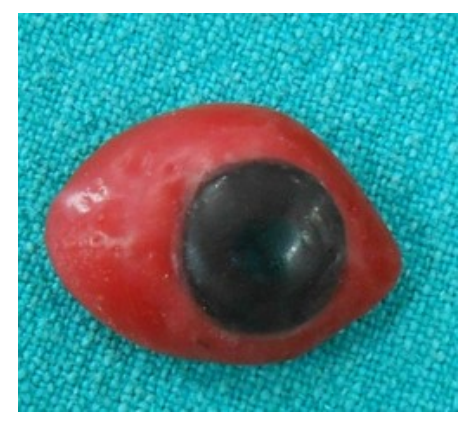

Fig 7: Prepared wax pattern

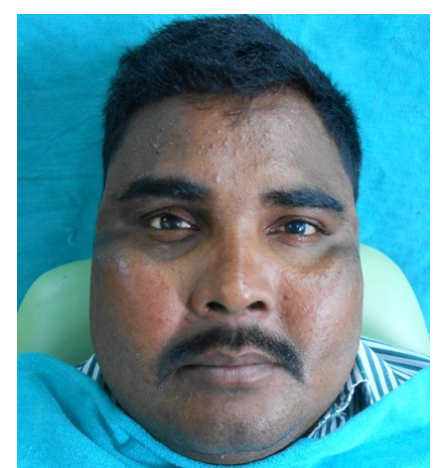

Fig 10: Post prosthetic rehabilitation
Fig 8: Wax pattern fitted with acrylic mount

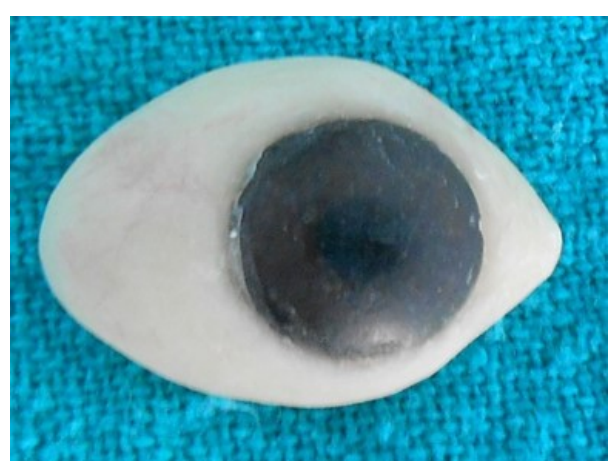

Fig 9: Final prosthesis 
Department of Prosthodontics, College of Dental Surgery, BPKIHS, Dharan with the chief complaint of missing right eye. Patient history revealed that he had a mechanical injury to the right eye 2 months back, due to which he underwent surgical removal (enucleation). Careful evaluation of the surgical site (fig 1) revealed absence of pain or irritation and there were no visible signs of infection. The tissue bed was normal and the relationship of palpebral fissure in an open and closed condition was also normal with normal control of palpebral muscles. The depth between the fornices was adequate. A custom ocular prosthesis was planned for the patient.

The patient's eye socket was coated with vaseline and primary impression was made using irreversible hydrocolloid ( Zelgan 2002 , Dentsply ) followed by fabrication of custom tray with screwing syringe tip (fig 2). The final impression was made with light body addition silicone impression material ( Reprosil, Dentsply ) (fig 3).

For final impression, the patient was seated upright with head supported at the head rest of the dental chair and instructed to hold his gaze in a straight forward position. The custom tray was placed in the socket and impression was made by injecting the light body silicone material through the screwing syringe tip into the custom tray filling the whole eye socket with the material. The patient was then asked to close his eye in order to allow the excess material to escape and then perform various eye movements to record a functional impression. The impression was then retrieved and checked for impression details.

A two pour technique was carried out using type IV Gypsum (Kalrock, Kalabhai Dental, India) to obtain the working cast. A wax pattern was made by pouring modelling wax into the functional defect area of the cast. A tooth colored acrylic shade guide was used and the scleral portion of the natural contra lateral eye was matched to obtain the shade of the scleral portion of the prosthesis.

Try- in of the wax pattern was done to verify size and support from the tissues in order to achieve ease of simulation of eye movement and eyelid coverage. The patient was instructed to fix the gaze of the natural eye on an object at least 3 feet in front and at eye level. The position of iris was determined by centering in relation to the inner and outer canthus and upper and lower lids (fig 5). The iris portion of the prosthesis was obtained from a stock eye shell matching the other eye (fig 6) and was inserted in the wax pattern followed by try-in (fig 7). During flasking, the iris shell was secured in its determined position using an acrylic mount (fig 8). After dewaxing procedure, packing and curing were done with the selected shade of heat cure tooth colored acrylic resin (DPI Heat polymerised tooth colored acrylic resin, Mumbai, India) incorporated with red nylon fibers to simulate the blood vessels of the contra lateral natural eye.

The prosthesis was recovered, polished, disinfected and inserted in patient's left eye socket. During insertion, the ocular prosthesis was evaluated for its esthetics, retention, comfort and ease of performing various eye movements. Post insertion instructions were given for insertion and maintenance of prosthesis.

\section{DISCUSSION}

Replacement of lost eye as soon as possible after healing from surgery is necessary to promote physical and psychological healing for the patient and to improve the social acceptance. Various treatment options available are autogenous surgical reconstruction, prosthetic reconstruction using implants and ocular prosthesis. Ocular prosthesis may be prefabricated or custom made. Prefabricated prosthesis carries potential disadvantages of poor fit, poor esthetics and poor eye movements. ${ }^{9}$ A custom ocular prosthesis has advantage of close adaptation to the tissue bed, provides maximum comfort and restores full physiological function to the accessory organs of the eye. ${ }^{10}$

\section{CONCLUSION}

For a good and comfortable prosthesis, better techniques along with a better understanding of mental attitude of patients should be considered. This case report explains use of a prefabricated ocular prosthesis to fabricate custom made ocular prosthesis hence providing patient with an economical yet esthetically and functionally better prosthesis than a stock eye prosthesis.

\section{REFERENCES}

1. Raflo GT. Enucleation and evisceration. In: Tasmun W, Jaeger E, editors. Duane's clinical ophthalmology. Rev. ed. Vol. 5. Philadelphia: LippincottRaven; 1995. p. 1-25.

2. Perman KI, Baylis HI. Evisceration, enucleation, and exenteration. Otolaryngol Clin North Am 1988;21:171-82.

3. The glossary of prosthodontic terms. J Prosthet Dent 2005 ; 48-49.

4. Chalian VA, Drane JB, Standish MS. Maxillofacial 
Prosthetics: Multidisciplinary Practice. Baltimore: The Williams \& Wilkins Co; 1971. p. 286-93.

5. Chiramana S, Anne G, Ravuri K, Boppana PP, Kumar S, Appana KC. A time saving method to fabricate a custom ocular prosthesis. J Orofac Res 2013;3:42-5. DOI: 10.5005/jp-journals-10026-1062.

6. Sinha ND, Bhandari AJ, Gangadhar SA. Fabrication of custom ocular prosthesis using a graph grid. Pravara Med Rev 2009;4:21-4.

7. Debnath N, Gupta R, Meenakshi A, Ramkumar K, John J. A simplified approach to fabricate a custom - madeocular prosthesis. Int J Prosthodont Res Dent 2013;3:25-9.

8. Ow RK, Amrith S. Ocular prosthetics: use of a tissue conditioner material to modify a stock ocular prosthesis. J Prosthet Dent 1997;78:218-22. DOI: 10.1016/S0022-3913 (97)70129-X.

9. Cain JR. Custom ocular prosthesis. JProsthet Dent 1982;48:690-4. DOI: 10.1016/S0022-3913(82)80030-9.

10. Benson P. The fitting and fabrication of acustom resin artificial eye. J Prosthet Dent1977;38:532-8. DOI: 10.1016/0022-3913(77)90029-4. 